\title{
The investigation of media components for optimal metabolite production of Aspergillus terreus ATCC 20542
}

\begin{abstract}
Purpose: This study aimed to assess the effect of nitrogen, salt and pre-culture conditions on the production of lovastatin in A. terreus ATCC 20542. Methods: Different combinations of nitrogen sources, salts and pre-culture combinations were applied in the fermentation media and lovastatin yield was analysed chromatographically. Result: The exclusion of $\mathrm{MnSO}_{4}$ $\cdot 5 \mathrm{H}_{2} \mathrm{O}, \mathrm{CuSO}_{4} \cdot 5 \mathrm{H}_{2} \mathrm{O}$ and $\mathrm{FeCl}_{3} \cdot 6 \mathrm{H}_{2} \mathrm{O}$ were shown to significantly improve lovastatin production $\left(282 \%\right.$ ), while $\mathrm{KH}_{2} \mathrm{PO}_{4}, \mathrm{MgSO}_{4} \cdot 7 \mathrm{H}_{2} \mathrm{O}$, and $\mathrm{NaCl}$ and $\mathrm{ZnSO} 4 \cdot 7 \mathrm{H}_{2} \mathrm{O}$ were indispensable for good lovastatin production. Simple nitrogen source (ammonia) was unfavourable for morphology, growth and lovastatin production. In contrast, yeast extract (complex nitrogen source) produced the highest lovastatin yield $(25.52 \mathrm{mg} / \mathrm{L})$, while powdered soybean favoured the production of co-metabolites ((+)-geodin and sulochrin). Intermediate lactose: yeast extract $(5: 4)$ ratio produced the optimal lovastatin yield $(12.33 \mathrm{mg} / \mathrm{L})$ during preculture, while high $(5: 2)$ or low $(5: 6)$ lactose to yeast extract ratio produced significantly lower lovastatin yield ( $7.98 \mathrm{mg} / \mathrm{L}$ and $9.12 \mathrm{mg} / \mathrm{L}$, respectively). High spore concentration, up to 107 spores/L was shown to be beneficial for lovastatin, but not for co-metabolite production, while higher spore age was shown to be beneficial for all of its metabolites. Conclusion: The findings from these investigations could be used for future cultivation of A. terreus in the production of desired metabolites.
\end{abstract}

Keyword: Aspergillus terreus; Lovastatin; (+)-geodin; Sulochrin; Media 